fluorescence than the rest. Dr. P. M. A. Rabbit and $\mathrm{Mr}$. S. M. Vyas, of the Institute of Experimental Psychology at Oxford, are investigating the speed with which a person responds to a visual stimulus in relation to whether a previous stimulus was the same or different. They showed that, as might be expected, the second response was faster than the first if the two stimuli were similar in characters that had to be watched for. But they also showed that other characters not watched for quickened the response even more. Thus the first response seems to depend on a perception of the whole displayed object rather than individual features of it.

Since much the greater part of the earth's surface is covered with water, it is only right that we should be deeply concerned about its denizens, and two exhibits were on this theme. The Government's Fisheries Radiobiological Laboratory at Lowestoft in Suffolk controls the main discharges of radioactive waste into lakes, rivers, and seas, giving advice as well as monitoring the disposal of this most dangerous of man's effluvia. Among its investigations is one into the chronic effects of gamma-radiation on fish. Government laboratories at Burnham on Crouch in Essex and at Pitlochry in Perthshire also had a joint demonstration of their work on the monitoring of pesticides in fish.

These two exhibits are symptomatic of a slight change in emphasis on the direction of scientific research. Though it may be carried out primarily to satisfy man's curiosity, the justification is commonly advanced that research is for his benefit. Now the question is being asked whether it is also for the benefit of other living organisms for the destruction of species and their habitats in the last hundred years is nothing less than alarming.

\section{Riots and Health}

In all conflicts the combatants make the headlines, their destruction provides the pictures, the underlying issues are the subject of public discussion. And always, peaceful people are drawn into the strife, their suffering is bitter, and most of the time it passes unnoticed. Now two psychiatrists have attempted to measure the effects of this suffering by recording the incidence of psychiatric disorder after the rioting in Belfast in August and September 1969.

R. M. Fraser ${ }^{1}$ has made a controlled retrospective survey of hospital records, which showed no increase in the numbers of patients referred to psychiatrists or admitted to psychiatric wards from areas directly involved in rioting, though there was a highly significant increase in the number of prescriptions given for tranquillizers. From areas where the disturbance was "comparatively slight" there were substantial increases in psychiatric referrals and admissions, but no great change in the prescriptions for tranquillizers.

H. A. Lyons ${ }^{2}$, also retrospectively, studied the reaction pattern of 217 patients seen by general practitioners and 40 referred to psychiatrists, all of whose psychiatric symptoms were judged to be related to the riots. The whole range of psychiatric symptomatology was observed, but "acute situational anxiety" or "anxiety state" was the diagnosis for over two-thirds. Just over half of these gave no history of previous psychiatric disorder, while only a quarter of those with other diagnoses gave no previous psychiatric history. Psychotic reactions were rare.

The two papers are broadly in agreement. Fraser's results suggest that the proximity to and the threat of violence may produce mental disorder (classified as either "neurotic" or "psychotic"), but that the actual experience of rioting and burning led only to increases in prescriptions for tranquillizers. They were presumably given to patients with acute anxiety symptoms, such as Lyons's patients, all of whom were drawn from the riot areas.

These findings invite comparison with the effects of the bombing of Britain on the mental health of civilians in the second world war. The two large surveys of $\mathrm{A}$. Lewis ${ }^{3}$ and C. P. Blacker ${ }^{4}$ show that the rise was minimal, and these with other published accounts suggest that acute anxiety reactions were rare. But in war the issues are clear-cut, the enemy can easily be identified, and there is general dedication to the war effort. In civil conflict the objectives are far from clear, the enemy may be ill-defined, and no refuge is really secure. If there is any solidarity it is purely local, so that morale is likely to be rather low, and political wrangling is apt to weaken it anyway. Persistent fear, uncertainty, and frustration in face of a threat which cannot be precisely identified provides a setting for stress symptoms of any kind. After months of strife in Belfast there may now be a large number of people who are showing measurable signs of distress. But what are the appropriate measures?

Fraser and Lyons showed that there was no dramatic increase in mental ill health, and that is in line with the wartime reports. Studies of the incidence of physical conditions tell another story. J. N. Morris and R. M. Titmuss ${ }^{5}$ found a substantial rise in deaths from peptic ulcer in London after the air raids of 1940 , while they rose only slightly in the rest of England and Wales. The United States Strategic Bombing Survey of Europe $^{6}$ reported that an "analysis of data from governmental insurance groups demonstrates an unmistakable increase in the incidence of ulcer patients during the war years and especially during periods in which the particular areas were subjected to bombing. Furthermore, the areas which received little or no bombing showed little or no increase in the incidence of peptic ulcer." It also found "a distinct rise in the incidence of coronary heart disease." H. G. Wolff found a much higher than expected number of deaths from heart disease, cancer, accidents, suicide, and pulmonary tuberculosis among American servicemen who had been prisoners-of-war of the Japanese. After the Bristol floods of $1968 \mathrm{G}$. Bennet ${ }^{8}$ reported among the victims a substantial rise in the number of attendances at general practitioners' surgeries, referrals to hospital, and hospital admissions. And they had diagnoses of all kinds, not just those which might have been considered to be a direct consequence of flooding. Further, the mortality rate of those flooded increased by $50 \%$ over the subsequent 12 months.

People respond to civil disaster much as they respond to a bereavement, and an increased morbidity and mortality among the bereaved has often been reported. It may be therefore that these reports from Belfast are understating the real situation, that the people's suffering will turn out to be even greater than had been supposed, and that it will not stop when the last bullet has been fired.

1 Fraser, R. M., British fournal of Psychiatry, 1971, 118, 257

Lyons, H. A., British Fournal of Psychiatry, 1971, 118, 265.

3 Lewis, A., Lancet, 1942, 2, 175.

Blacker C. P., Neurosis and the Mental Health Services, London, Oxford, 1946

Morris, J. N., and Titmuss, R. M., Lancet, 1944, 2, 841.

United States Strategic Bombing Survey, The Effect of Bombing on Health and Medical Care in Germany. Washington D.C., U.S. Go rernment Printing Office, 1945, p. 99.

Wolf, H. G., in Stress and Psychiatric Disorder, ed. J. M. Tanner, p. 29. Oxford, Blackwell, 1960. 